\title{
SARCOIDOSIS- A CLINICORADIOLOGICAL PROFILE OF 30 PATIENTS
}

\author{
Avdhesh Kumar', Brijesh Kumar², Anand Kumar 3 , Sanjay Kumar Verma ${ }^{4}$, Sanjeev Rohtagi ${ }^{5}$, Anshul Jain ${ }^{6}$, Sudhir Chaudhri ${ }^{7}$, Surya Kant ${ }^{8}$ \\ ${ }^{1}$ Assistant Professor, Department of Tuberculosis \& Respiratory Diseases, GSVM Medical College, Kanpur. \\ ${ }^{2}$ Assistant Professor, Department of Internal Medicine, Government Medical College, Kannauj. \\ ${ }^{3}$ Associate Professor \& HOD, Department of Tuberculosis \& Respiratory Diseases, GSVM Medical College, Kanpur. \\ ${ }^{4}$ Associate Professor, Department of Tuberculosis \& Respiratory Diseases, Government Medical College, Kannauj. \\ 5 Professor, Department of Ophthalmology, Government Medical College, Kannauj. \\ 6Junior Resident, Department of Tuberculosis \& Respiratory Diseases, GSVM Medical College, Kanpur. \\ 7 Professor, Department of Tuberculosis \& Respiratory Diseases, GSVM Medical College, Kanpur. \\ sProfessor \& HOD, Department of Pulmonary Medicine, King George's Medical University, UP, Lucknow, India.
}

\section{ABSTRACT}

\section{BACKGROUND}

Sarcoidosis is an inflammatory multisystem granulomatous disease of unknown aetiology and predominantly affects the lungs, followed by eye, skin, peripheral lymph node, liver, spleen, heart, central nervous system, musculoskeletal system and salivary glands.

Aim- To find out the clinical profile of sarcoidosis patients prospectively admitted to a respiratory unit.

\section{MATERIALS AND METHODS}

The study was conducted on 30 patients of sarcoidosis, who were admitted for various respiratory complaints, in the Department of Pulmonary Medicine, GSVM Medical College, Kanpur \& Govt. Medical College, Kannauj. A thorough respiratory evaluation was done including clinical evaluation for signs and symptoms, chest x-ray PA view, HRCT Thorax, Spirometry, sputum for AFB, PPD, serum ACE, serum Calcium, 24-hour urinary calcium, BAL Fluid analysis, CD4 to CD8 of BAL fluid.

\section{RESULTS}

30 patients of sarcoidosis were evaluated. Of the total patients, male \& female were 11 and 19 respectively and ratio was $1: 1.7$. The mean age of study group was 34.8 years (Range 27-51). Dyspnoea was present in all the patients followed by dry cough (93.3\%). Bilateral hilar lymphadenopathy plus pulmonary opacity was the most common radiological presentation of sarcoidosis in $14 / 30$ (46.7\%). Pleural effusion was noted in a single case. Extrapulmonary manifestations like subcutaneous nodules were seen in only one case while uveitis also observed in single case only. Sputum for AFB was negative in 2 cases, while others did not raise sputum. PPD testing showed no induration among all, except one where it showed mild induration (6 mm). Serum ACE was elevated in $24 / 30$ patients $(86.6 \%)$. Serum Calcium was elevated in $10 / 30$ patients (28.6\%). 24-hour urinary calcium was elevated in $8 / 30$ patients (26.6\%). Spirometry showed a restrictive pattern in $71.4 \%$ (i.e. $20 / 28$ ) and was normal in $17.9 \%$ cases while the other three patients did not cooperate. The CD4 to CD8 of BAL fluid levels were raised in all cases of sarcoidosis (range 2.9-4.4).

\section{CONCLUSION}

Bilateral hilar lymphadenopathy plus pulmonary opacity was the most common radiological presentation of sarcoidosis and BAL fluid CD4 to CD8 counts are easy to perform and helpful in supporting diagnosis of sarcoidosis along with clinical and radiological features.

\section{KEYWORDS}

Sarcoidosis, Hilar Lymphadenopathy, Serum ACE, BAL fluid.

HOW TO CITE THIS ARTICLE: Kumar A, Kumar B, Kumar A, et al. Sarcoidosis- A clinicoradiological profile of 30 patients. J. Evolution Med. Dent. Sci. 2017;6(45):3507-3513, DOI: 10.14260/Jemds/2017/757

\section{BACKGROUND \\ Sarcoidosis is a multisystem, inflammatory disorder of unknown aetiology that affects individuals worldwide. This disease shows a consistent predilection for adults less than 40 years of age with slightly higher disease rate for women. ${ }^{1}$}

Financial or Other, Competing Interest: None.

Submission 20-04-2017, Peer Review 24-05-2017,

Acceptance 29-05-2017, Published 05-06-2017.

Corresponding Author:

Dr. Sanjay Kumar Verma,

Associate Professor,

Department of Tuberculosis \& Respiratory Diseases,

Government Medical College,

Kannauj, Uttar Pradesh.

E-mail: drskverma78@rediffmail.com

DOI: $10.14260 /$ jemds $/ 2017 / 757$
Sarcoidosis involves the bronchi or lung in more than 90 percent of patients and intrathoracic manifestations are protean, ranging from asymptomatic bilateral hilar lymphadenopathy to chronic, progressive, (ultimately fatal), respiratory insufficiency. In sarcoidosis, diagnosis is established on the basis of clinicoradiological features supported by histopathological evidence of non-caseating granulomas after exclusion of known causes (tuberculosis, leprosy, fungal infection). ${ }^{1-2}$

The true burden of sarcoidosis in India is not clearly known as reliable epidemiological data are not available. In India, the first reported biopsy proven case of sarcoidosis was reported from Calcutta in 1956.3-4 Another study from India reported 190 biopsy proven cases of sarcoidosis from 1972 to 1998 and another 206 cases have been discovered, while searching through the existing literature in this 
country. ${ }^{5}$ Due to high prevalence of TB in India and also the resemblance in clinicoradiological features, sarcoidosis in India frequently gets treated as TB. ${ }^{6}$

The aim of present study was to determine the clinicoradiological profile of pulmonary sarcoidosis in the Indian context.

\section{MATERIALS AND METHODS}

The present case series consisted of 30 consecutive patients who attended the outpatient and inpatient section, at the Department of Tuberculosis and Respiratory Diseases and Department of Internal Medicine, G.S.V.M. Medical College, Kanpur (India) from September 2009 to August 2016.

A detailed clinical history and physical examination was carried out in all the patients. This was followed by haemogram, chest radiography, sputum smear examination for acid-fast bacilli (AFB) on two consecutive days, Mantoux test, spirometry, serum angiotensin converting enzyme (ACE) levels, serum calcium, PPD, Urinary calcium and high resolution computed tomography of thorax (HRCT).

Chest radiographs were classified by Scadding stages:

0 - normal chest radiographic findings; I- bilateral hilar adenopathy with normal lung parenchyma; II- bilateral hilar adenopathy with pulmonary infiltrates; III- pulmonary infiltrates without hilar adenopathy; IV- pulmonary fibrosis/fibrocystic parenchymal changes. ${ }^{7}$

The diagnosis of sarcoidosis was based upon compatible clinical, radiological, laboratory and/or histologic demonstration of noncaseating granulomas, and exclusion of other diseases capable of producing a similar histologic or clinical picture (ATS/ERS/WASOG). ${ }^{1}$

In the presence of a compatible clinical picture, the first step is to choose the site for a proper biopsy. Transbronchial lung biopsy (TBLB) is the recommended procedure in most cases and its diagnostic yield depends largely on the experience of the operator, ranging from $40 \%$ to more than $90 \% .8$ When bronchial or transbronchial biopsies are nondiagnostic, and no other accessible sites for biopsy are identified, surgical lung biopsy may be indicated. The finding of mediastinal adenopathy on the conventional CT scan should prompt biopsy by mediastinoscopy before videoassisted thoracoscopic lung biopsy (VTLB) or open lung biopsy. The diagnostic yield of all of these procedures are reported to be more than $90 \% \cdot{ }^{9-10}$

The diagnosis of sarcoidosis in patients without histology is usually based upon clinical and/or radiological features. The clinical and/or radiological features alone may be diagnostic for patients with Stage I (reliability of 98\%) or Stage II (89\%) disease, but are less accurate for patients with Stage III (52\%) or Stage 0 (23\%) disease. ${ }^{11}$ In some instances, bronchoalveolar lavage (BAL) and studies on lymphocyte subpopulations are helpful. According to Costabel, a BAL fluid CD4/CD8 ratio greater than 3.5 has a sensitivity of 53\%, a specificity of $94 \%$, a positive predictive value of $76 \%$ and a negative predictive value of $85 \% .{ }^{12}$ In other words, a BAL fluid CD4/CD8 ratio $>3.5$ provides a diagnosis of sarcoidosis with a specificity of $94 \%$ even if the TLB has not been diagnostic.

In patients who were either not fit to undergo FOB or refused to undergo the same, the diagnosis was made on the basis of clinical, laboratory and radiological features and response to corticosteroid treatment.

\section{RESULTS}

Of the 30 patients, with sarcoidosis, 11 were males while 19 were females (Ratio M: F; 1:1.7). The mean age of study group were 34.8 years (Range 27-51). Mean duration of respiratory complaints was 8.7 months (Range 2-14 months). Dyspnoea was present in all the patients followed by dry cough $(93.3$ $\%)$. Sputum for AFB was negative in all patients. $31.5 \%$ cases of sarcoidosis, misdiagnosed as pulmonary tuberculosis and had a history of anti-tubercular treatment. This might be due to radiological similarities between sarcoidosis and pulmonary tuberculosis and a lack of awareness and paucity of diagnostic facilities.

Bilateral hilar lymphadenopathy plus pulmonary opacity (Stage II) was the most common radiological presentation of sarcoidosis in 14/ 30 (46.6 \%). HRCT thorax revealed enlarged intrathoracic lymph nodes in 25 (92.3\%) cases, GGO in 15 (53.8\%) cases, Inter septal thickening in 8 (30.7\%) cases, honey combing in 4 (15.4\%) cases and Pleural effusion in $1(12.5 \%)$ case. Extrapulmonary manifestation of sarcoidosis was observed in two cases, one had erythema nodosum and another had uveitis. Spirometry showed restrictive pattern in $80 \%$ cases (Mean FEV1/FVC 86 $\%$ and Mean FVC 1.16 Litre), while 3 (20\%) patients did not cooperate. (Table 1: Shows patient's characteristics of study group). PPD was negative in $93.3 \%$ cases. Serum ACE (> 40 U/L) was elevated in 24 cases (86.6\%). Hypercalcaemia (serum calcium $>10.5 \mathrm{mg} / \mathrm{dL}$ ) was observed in $10(33.3 \%$ ) cases. Hypercalciuria (24-hour urinary calcium $>300 \mathrm{mg} / \mathrm{dL}$ ) was seen in 8 (26.6\%) patients. Bronchoscopic findings of nodules and erythema were observed in 6 and $4 \%$ cases respectively.

FOB, were performed in all the patients and bronchial aspirate was negative for AFB in all the patients. BAL Fluid CD4 to CD8 ratio was elevated in all cases of sarcoidosis (Mean: 3.6, Range- 2.9-4.4). Others system were within normal limits. TBLB was performed only among 11 patients who underwent bronchoscopy $(\mathrm{n}=30)$; histopathological examination revealed non-caseating granulomas in 8 (72.7\%). In 22 patients diagnosis of sarcoidosis was made on the basis of compatible symptoms and signs and/or raised serum ACE levels, negative Mantoux test, suggestive chest radiograph, HRCT thorax findings and raised BAL fluid CD4/CD8 ratio and this was further confirmed on follow-up by clinical and radiological response to corticosteroids.

In present case series, of the 12 patients (40\%) with type -I sarcoidosis, 10 were treated and 2 were initially observed but later treated. Eleven (36.6\%) of these were cured and one (3.3\%) declared to have arrested disease. All the 14 patients with type-II sarcoidosis and 2 patients with type-III sarcoidosis and 2 patients with type-IV sarcoidosis were treated \& declared to have arrested disease. The one patient with extrathoracic sarcoidosis was declared cured after treatment. The mean duration of treatment were 13.8 months (range: 8-16 months) 


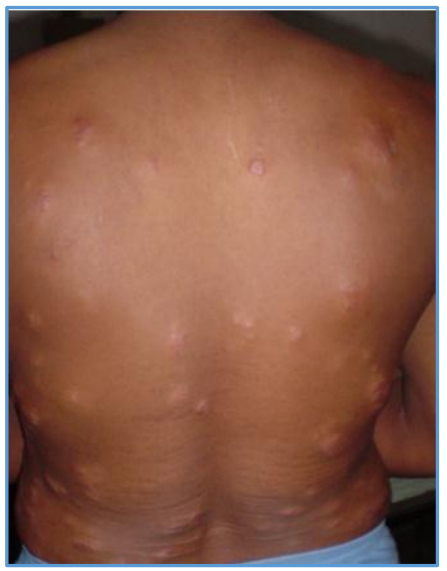

Figure 1. Showing Subcutaneous Nodular Lesions over the Back of Chest

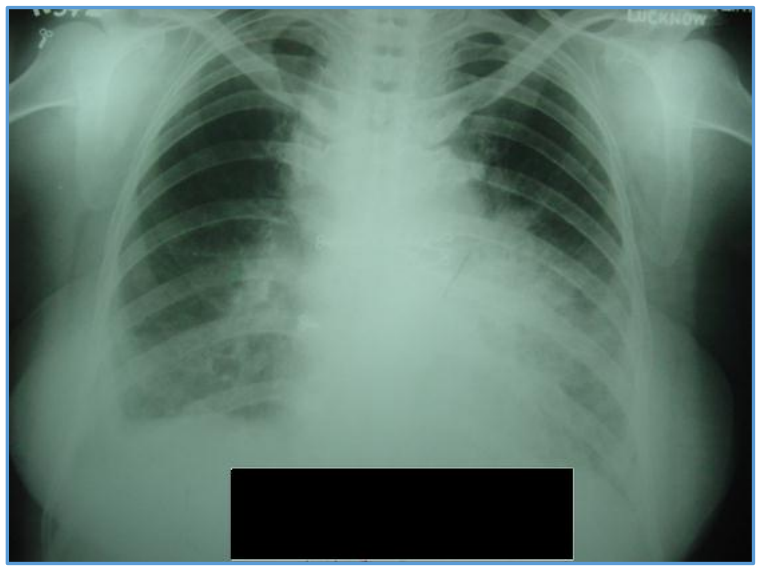

Figure 2. Chest X-ray of a 45-year-old Female reveals Right Paratracheal and Hilar Lymphadenopathy

\begin{tabular}{|c|c|c|c|c|}
\hline Sl. No. & \multicolumn{2}{|c|}{ Parameter } & Total Number & $\%$ \\
\hline \multirow{5}{*}{1} & \multirow{5}{*}{ Age } & 20-29 years & 2 & 6.7 \\
\hline & & $30-39$ years & 9 & 30 \\
\hline & & 40-49 years & 14 & 46.7 \\
\hline & & 50-59 years & 4 & 13.3 \\
\hline & & $>60$ Years & 1 & 3.3 \\
\hline \multirow{2}{*}{2} & \multirow{2}{*}{ Sex } & Females & 19 & 63.3 \\
\hline & & Males & 11 & 36.7 \\
\hline \multirow{4}{*}{3} & \multirow{4}{*}{ Radiographic staging } & Stage I & 12 & 40 \\
\hline & & Stage II & 14 & 46.7 \\
\hline & & Stage III & 2 & 6.7 \\
\hline & & Stage IV & 2 & 6.7 \\
\hline \multirow[b]{2}{*}{4} & \multirow[b]{2}{*}{ History of smoking } & Females & None & - \\
\hline & & Males & $\begin{array}{c}\text { (Mean Pack Years }=10.3, \\
\text { Range: } 7-14)\end{array}$ & 26.7 \\
\hline 5 & \multicolumn{2}{|c|}{ Past H/O of ATT } & 14 & 46.7 \\
\hline \multirow{3}{*}{6} & \multirow{3}{*}{ Symptoms } & Cough & 28 & 93.3 \\
\hline & & Breathlessness & 30 & 100 \\
\hline & & Chest pain & 5 & 16.7 \\
\hline \multirow{2}{*}{7} & \multirow{2}{*}{$\begin{array}{l}\text { Extrapulmonary } \\
\text { manifestations }\end{array}$} & Uveitis & 1 & 3.3 \\
\hline & & Subcutaneous nodule & 1 & 3.3 \\
\hline
\end{tabular}

\begin{tabular}{|c|c|c|c|c|c|c|c|c|c|}
\hline \multirow{2}{*}{$\begin{array}{l}\text { Sl. } \\
\text { No. }\end{array}$} & \multirow{2}{*}{$\begin{array}{l}\text { Name of } \\
\text { Authors }\end{array}$} & \multirow{2}{*}{ Country } & \multirow{2}{*}{$\begin{array}{c}\text { Year of } \\
\text { Publication }\end{array}$} & \multirow{2}{*}{$\begin{array}{c}\text { No. of } \\
\text { Patients }\end{array}$} & \multicolumn{5}{|c|}{ Radiographic Stage of Sarcoidosis (\%) } \\
\hline & & & & & $\mathbf{0}$ & I & II & III & IV \\
\hline 1 & Vishwanathan $\mathrm{R}$ & India & 1959 & 1 & \multicolumn{5}{|c|}{ Records Incomplete } \\
\hline 2 & De MS et al & India & 1968 & 1 & \multicolumn{5}{|c|}{ Records Incomplete } \\
\hline 3 & Guleria JR & India & 1971 & 4 & \multicolumn{5}{|c|}{ Records Incomplete } \\
\hline 4 & Gupta Samir & India & 1977 & 7 & \multicolumn{5}{|c|}{ Records Incomplete } \\
\hline 5 & Chakravarty SC & India & 1978 & 24 & \multicolumn{5}{|c|}{ Records Incomplete } \\
\hline 6 & Bambery $\mathrm{p}$ & India & 1987 & 40 & 2 & 53 & 30 & 15 & ND \\
\hline 7 & Kashyap & India & 1997 & 29 & 3 & 45 & 34 & 18 & $\mathrm{ND}$ \\
\hline 8 & Rosha & India & 2000 & 60 & 1 & 62 & 30 & 7 & ND \\
\hline 9 & Sharma SK & India & 2001 & 106 & 0 & 24 & 63 & 13 & ND \\
\hline 10 & R. Kumar & India & 2012 & 146 & 2.8 & 51.4 & 37.1 & 5.7 & 2.8 \\
\hline 11 & Present study & India & 2017 & 30 & - & 40 & 46.6 & 6.6 & 6.6 \\
\hline
\end{tabular}




\begin{tabular}{|c|c|c|c|c|c|c|c|c|c|}
\hline \multirow{2}{*}{$\begin{array}{l}\text { Sl. } \\
\text { No. }\end{array}$} & \multirow{2}{*}{$\begin{array}{l}\text { Name of } \\
\text { Authors }\end{array}$} & \multirow{2}{*}{ Country } & \multirow{2}{*}{$\begin{array}{c}\text { Year of } \\
\text { Publication }\end{array}$} & \multirow{2}{*}{$\begin{array}{c}\text { No. of } \\
\text { Patients }\end{array}$} & \multicolumn{5}{|c|}{ Radiographic Stage of Sarcoidosis (\%) } \\
\hline & & & & & $\mathbf{0}$ & I & II & III & IV \\
\hline 1 & Siltzbach LE & USA & 1967 & 244 & 0 & 45 & 39 & 16 & ND \\
\hline 2 & Romer FK & Denmark & 1982 & 243 & 0.4 & 55 & 40 & 4.5 & ND \\
\hline 3 & Hillerdal G & Sweden & 1984 & 505 & 3 & 61 & 25 & 10 & 1 \\
\hline 4 & Gupta SK & British Isles & 1985 & 818 & 14 & 56 & 18 & 11 & ND \\
\hline 5 & Hunninghake GW & USA & 1994 & 98 & 20 & 18 & 27 & 10 & 25 \\
\hline 6 & Gottlieb & USA & 1997 & 337 & 8 & 45 & 29 & 17 & ND \\
\hline 7 & Chappel AG & British Isles & 2000 & 212 & 9 & 51 & 20 & 15 & 5 \\
\hline 8 & Pietinalho A & Finland & 2000 & 437 & 0 & 44 & 43 & 13 & 0.4 \\
\hline 9 & Pietinalho A & Japan & 2000 & 457 & 0 & 67 & 27 & 5 & 0 \\
\hline 10 & Baughman RP & USA & 2001 & 736 & 8 & 40 & 37 & 10 & 5 \\
\hline 11 & Kitter G & Turkey & 2011 & 293 & 4.8 & 51.9 & 31.7 & 5.1 & 0.7 \\
\hline 12 & Fatih Ors & Turkey & 2013 & 45 & & 48.9 & 31.1 & 8.9 & 4.4 \\
\hline 13 & Carrillo-Perez DL & Mexico & 2014 & 21 & 42.9 & 29 & 9.5 & 9.5 & 9.5 \\
\hline
\end{tabular}

\section{DISCUSSION}

Sarcoidosis today is being more frequently recognised than earlier and is now seen as an important emerging disease in India. The true burden of sarcoidosis in India is not clearly known due to underreporting caused by its resemblance to TB. In the present study, $46.7 \%$ cases have been misdiagnosed as tuberculosis and had taken ATT before coming to our hospital.

The ATS/ERS/WASOG statement states that sarcoidosis consistently shows a predilection for adults under age 40; peaking in those aged 20-29 years. ${ }^{1}$ However, studies done in Scandinavian countries and Japan report a second peak in incidence in women aged over 50 years. ${ }^{13-14}$ Other studies from western countries also report more than $70 \%$ patients of sarcoidosis to be of less than 40 years of age. ${ }^{15}$ A study done from India among sarcoidosis patients revealed the average age of 46 years (range) and $70 \%$ of them were in $4^{\text {th }} / 5^{\text {th }}$ decades. ${ }^{16}$ Rajkumar et al reported average age of 43 years (range 22-70) in sarcoidosis patients and majority were aged more than 40 years. ${ }^{6}$ Another study from India reported average age of 40 years in sarcoidosis patients. ${ }^{17}$ In present study, the mean age of study population was 34.8 years (range: 27-61 years) and majority were in between 30-49 years.

Studies done globally report slightly higher disease rate for women in sarcoidosis.1,18 In the only population-based incidence study of sarcoidosis in the United States, rates were 5.9 per 100,000 person-years for men and 6.3 per 100,000 person-years for women. ${ }^{19}$ Various studies from India reported male predominance. ${ }^{20-21}$ Similar observations have been found in present case series also.

Till date the most accepted proposed pathogenic hypothesis is that various antigens could promote sarcoidosis in genetically susceptible individuals.1,22 It appears to occur more frequently in non-smokers. This inverse relationship between smoking and sarcoidosis has been observed in various other studies. ${ }^{23-24}$ In our study also, majority (73.3\%) of patients were non-smokers.

Cough, dyspnoea, dry cough and chest pain have been reported in one-third to one-half of the patients and haemoptysis rarely occurred.1,18,25 In the present study, pulmonary symptoms were the most common complaints with the predominance of dyspnoea (100\%) which was followed by cough $(93.3 \%)$ and chest pain in $16.6 \%$ of the sarcoidosis patients.

A negative Mantoux test has a high sensitivity value for the diagnosis of sarcoidosis. Even the Bacillus CalmetteGuerin vaccination administered during childhood has been found to have no correlation with a negative Mantoux reaction. ${ }^{26} \mathrm{~A}$ positive Mantoux test (irrespective of the size of reaction) in a suspected case of sarcoidosis should arouse strong suspicion of an alternate or an additional diagnosis of TB. ${ }^{27}$ In our study also, we found that Mantoux test was negative in $93.3 \%$ patients.

Certain laboratory tests such as serum angiotensin converting enzyme (ACE) level, while often helpful in corroborating the diagnosis, did not make the diagnosis of sarcoidosis definitive. ${ }^{28}$ Serum ACE levels are increased in $30 \%-80 \%$ of patients with sarcoidosis and may be a surrogate marker of total granuloma burden as noted by studies from western countries. ${ }^{29}$ In previous Indian studies, elevated serum ACE levels were documented in $70.5 \%$ patients. ${ }^{30-31}$ In the present study, elevated levels of serum ACE were observed in $86.6 \%$ of cases.

Hypercalcaemia occurs in about $10 \%$ of the patients with sarcoidosis and hypercalciuria is about three times more frequent and are due to dysregulated production of 1,25- $(\mathrm{OH})$ 2-D3 (calcitriol) by activated macrophages trapped in pulmonary alveoli and granulomatous inflammation. ${ }^{32-33}$ In present study, the hypercalcaemia and hypercalciuria were observed in $33.3 \%$ and $26.6 \%$ cases of sarcoidosis respectively.

Most series have found that stage I is the most common radiographic stage, but significant variability exists. ${ }^{1}$ Similarly, radiographic stages I and II have been reported to be the predominant stages in most studies from Scandinavia. ${ }^{34}$ In contrast to this, some studies from the United States and British Isles cite a disproportionate representation of radiographic stage III and IV disease. ${ }^{35-36}$ Previous studies from India 6,8 report that most of the radiographic abnormalities belonged to stage I and $\mathrm{II}, 21,37$ but another study 26 found that stage II and III were more common. ${ }^{38}$ In present study, the most common stage of sarcoidosis on presentation was found to be stage II (46.6\%) followed by stage I (40\%). (The details of different radiographic stages of sarcoidosis patients in various 
Indian, 6,16-17,21,37,39-43 \& international $18,34,36,38,44-51$ studies are summarised in table 2 and table 3 ).

The classic radiographic feature of sarcoidosis is bilateral hilar lymphadenopathy and is reported to be present in nearly three quarters of patients. ${ }^{1}$ Previous studies have found that right paratracheal lymph nodes may be also be involved concomitantly. ${ }^{29,34}$ Computed tomography (CT) may reveal the enlargement of left paratracheal, paraaortic, and subcarinal lymph node groups also. ${ }^{52}$ In present study, we found hilar/mediastinal lymphadenopathy on CT $(n=27)$ in 92.6\% patients. Unilateral hilar lymph node enlargement has been reported as being uncommon (seen in $<10 \%$ ) in the West. ${ }^{28}$ In our series, it was not seen in any of the patients.

In sarcoidosis, cutaneous involvement occurs in about $25 \%$ of patients.53 Two clinically important and easily recognisable skin lesions are erythema nodosum and lupus pernio. Erythema nodosum is the hallmark of acute sarcoidosis and the lesion consists of raised, red, tender bumps or nodules on the anterior aspects of the legs. Lupus pernio represents chronic sarcoidosis and consists of indurated plaques associated with discolouration of the nose, cheeks, lips, and ears. Other skin lesions in chronic sarcoidosis include plaques, maculopapular eruptions, subcutaneous nodules, changes in old scars, alopecia, and hypo- and hyperpigmented areas. In present case series, one patient had multiple subcutaneous nodules (Figure: 1). ACCESS study group found prevalence of skin involvement (excluding erythema nodosum) in United States of America to be $15.9 \%$ and erythema nodosum was observed in $8.3 \% .^{18}$ Yanardag $\mathrm{H}$ et al retrospectively evaluated the clinical features of patients diagnosed as sarcoidosis and who had skin involvement.54 They had observed cutaneous involvement in 170 patients (136 females, 34 males) and the most frequent skin lesion was erythema nodosum (20.5\%), followed by subcutaneous nodules $(4.3 \%)$, maculopapular eruptions (3.7\%), scar lesions (2.9\%), lupus pernio (LP) $(2.7 \%)$ and psoriasiform plaques $(0.9 \%)$.

Joint pains occur in 25 to $39 \%$ of patients with sarcoidosis and deforming arthritis is rare. ${ }^{29}$ The joints most commonly affected are knees, ankles, elbows, wrists, and small joints of the hands and feet. In present case series, $23.3 \%$ patients had symptoms of joint pain.

Ocular involvement may occur in 11 to $83 \%$ of patients with sarcoidosis.55 Any part of the eye or orbit may be affected; uveitis is the most common of all sarcoid eye lesions. In present case series, one patient had symptoms of chronic uveitis.

In patients of suspected pulmonary sarcoidosis, the initial diagnostic procedure of choice is flexible fibreoptic bronchoscopy (FOB) with transbronchial lung biopsy (TBLB). ${ }^{8,29}$ The bronchial mucosa in sarcoidosis may appear normal, erythematous, miliary or large nodules, yellowish nodules with a cobblestone appearance and occasionally, endobronchial granulomas form a mass-like lesion that can obstruct the bronchial lumen. ${ }^{56-58}$

The prevalence of abnormal bronchial mucosa in sarcoidosis has been reported to vary from 33\% to $70 \%$ in differentstudies. ${ }^{57,59}$ Torrington et al reported that both black and white patients with sarcoidosis had abnormal mucosa in approximately half of the patients. ${ }^{60}$ In present study, we found bronchial mucosa involvement in the form of erythema in $6.1 \%$, plaques in $3.8 \%$ and nodules in 12.2 percent.
Fibreoptic bronchoscopy is a safe and minimal invasive procedure, available to make the diagnosis, including needle aspiration, BAL, transbronchial biopsy, open-lung biopsy, and mediastinoscopy. ${ }^{25}$ Each of these techniques has advantages and disadvantages. BAL is safe, minimally invasive, and provides useful information for the diagnosis of sarcoidosis. The characteristic findings in BAL for sarcoidosis are normal or only mildly elevated total cell count with a predominance of lymphocytes, usually a normal percentage of eosinophils and neutrophils, and an absence of plasma cells and foamy alveolar macrophages. ${ }^{61}$ Drent $\mathrm{M}$ et al reported that no single cell type present in bronchoalveolar lavage (BAL) fluid appears to be predictive for sarcoidosis. They also highlighted that in sarcoidosis the majority of cases have an increased number of lymphocytes and a normal number of eosinophils/neutrophils and in severe cases the number of neutrophils can be increased as well. ${ }^{62}$ The cell discrimination findings of BALF in the present study were revealed the predominance of lymphocytic plus neutrophilic and lone lymphocytic alveolitis.

Bronchoalveolar lavage CD4/CD8 ratios may be of diagnostic value in sarcoidosis, obviating the need of biopsy in $40-60 \%$ of patients and it may depend on the individual facilities, knowledge and skill of the investigators involved in the various diagnostic techniques. ${ }^{1}$ Costabel et al reported that a BAL fluid CD4/CD8 ratio of 3.5 or greater had a sensitivity of $52 \%$ and specificity of $94 \%$ in 117 consecutive patients with biopsy-proven sarcoidosis. ${ }^{12}$ Winterbauer et al described that a ratio of 4.0 or greater distinguished ${ }^{27}$ patients with sarcoidosis from 28 patients with other interstitial lung diseases with a sensitivity of $59 \%$ and a specificity of $96 \% .63$ Thomeer and Demedts compared ${ }^{42}$ patients with sarcoidosis and 90 patients with other forms of diffuse lung disease and found that a CD4/CD8 ratio of greater than 4.0 had a sensitivity of $55 \%$ and a specificity of 94\%.64 These three studies reached similar conclusions: in patients with a clinical picture typical of sarcoidosis, an elevated CD4/CD8 ratio in BAL may prove diagnostic of sarcoidosis and obviate the need for confirmation by additional biopsy. It is important to note that in the study of Winterbauer et al, transbronchial biopsy had a specificity of $89 \%$ for the distinction between sarcoidosis and other forms of diffuse lung disease and was thus not better than the CD4/CD8 ratio in this respect.63 SP Kantrow et al reported that in pulmonary sarcoidosis BAL fluid CD4/CD8 ratio is highly variable and these authors found that only $42 \%$ in a population of 86 patients with biopsy-proven sarcoidosis had a ratio greater than 4.0 , and that $12 \%$ had an inversed ratio below 1.0.65

Danila E et al prospectively evaluated diagnostic role of BALF CD4/CD8 ratio in pulmonary sarcoidosis manifested in different radiographic and clinical forms and they found Normal BALF cell counts in $7 \%$ of sarcoid patients. They also found that optimal cut-off points for CD4/CD8 ratio are 3.5 and 4.0 for asymptomatic and symptomatic patients, respectively. ${ }^{66}$ In the present study, TBLB was performed in $36.6 \%$ of the patients (i.e. $11 / 30$ ) and more than half of them were diagnostic (i.e.8/11).

\section{CONCLUSION}

Sarcoidosis is a chronic granulomatous inflammatory disorder of unknown origin with heterogeneous outcome and not uncommon in India. The clinical and radiological features 
of sarcoidosis closely resemble tuberculosis and in countries with high prevalence of $\mathrm{TB}$, like India, it is often misdiagnosed. In present study, bilateral hilar lymphadenopathy plus pulmonary opacity was the most common radiological presentation of sarcoidosis. In present study, TBLB was performed in 11 patients only (i.e. 11/30); histopathological examination revealed non-caseating granulomas in $8(72.7 \%)$ patients. The present study also highlighted that the CD4 to CD8 of BAL fluid levels were raised in all cases of sarcoidosis and are easy to perform and helpful in supporting diagnosis of sarcoidosis along with clinical and radiological features.

\section{REFERENCES}

[1] Statement on sarcoidosis. Joint statement of the American thoracic society (ATS), the European respiratory society (ERS) and the world association of sarcoidosis and other granulomatous disorders (WASOG) adopted by the ATS board of directors and by the ERS executive committee, February 1999. Am J Respir Crit Care Med 1999;160(2):736-55.

[2] Judson MA. Sarcoidosis: clinical presentation, diagnosis, and approach to treatment. Am J Med Sci 2008;335(1):26-33.

[3] Ghosh PK, Chakraborty AN. Sarcoidosis. Bull School Trop Med 1956;4:142-3.

[4] Gupta SK. Sarcoidosis in India. Lung India 1989;7:53-4.

[5] Gupta SK, Dutta SK. Diagnostic delay and difficulties in sarcoidosis in eastern India. Lung India 1999;17(4):107-11.

[6] Kumar R, Goel N, Gaur SN. Sarcoidosis in north Indian population: a retrospective study. Indian J Chest Dis Allied Sci 2012;54(2):99-104.

[7] Scadding JG. Prognosis of intrathoracic sarcoidosis in England. A review of 136 cases after five years' observation. Br Med J 1961;2(5261):1165-72.

[8] Gilman MJ, Wang KP. Transbronchial lung biopsy in sarcoidosis. An approach to determine the optimal number of biopsies. Am Rev Respir Dis 1980;122(5):721-4.

[9] Raghu G. Interstitial lung disease: a diagnostic approach. Are CT scan and lung biopsy indicated in every patient? Am J Respir Crit Care Med 1995;151(3 Pt 1):909-14.

[10] Gossot D, Toledo L, Fritsch S, et al. Mediastinoscopy vs thoracoscopy for mediastinal biopsy. Results of a prospective nonrandomized study. Chest 1996;110(5):1328-31.

[11] Hiraga Y, Hosoda Y. Acceptability of epidemiological diagnostic criteria for sarcoidosis without histological confirmation. In: Mikami R, Hosoda $\mathrm{Y}$, (eds). Sarcoidosis. University of Tokyo Press, Tokyo 1981:373-7.

[12] Costabel U, Zaiss AW, Guzman J. Sensitivity and specificity of BAL findings in sarcoidosis. Sarcoidosis 1992;9(Suppl 1):211-4.

[13] Alsbirk PH. Epidemiologic studies on sarcoidosis in Denmark based on a nationwide central register. A preliminary report. Acta Med Scand 1964;425:106-9.

[14] Iwai K, Sekiguti M, Hosoda Y, et al. Racial difference in cardiac sarcoidosis incidence observed at autopsy. Sarcoidosis 1994;11(1):26-31.
[15] Milman N, Selroos O. Pulmonary sarcoidosis in the Nordic countries 1950-1982. Epidemiology and clinical picture. Sarcoidosis 1990;7(1):50-7.

[16] Rosha D, Panda BN. Sarcoidosis in India: an evaluation of 60 Cases. Lung India 2000;18(3):70-3.

[17] Chakravarty SC, Damodaran VN. Sarcoidosis in India. J Ind Med Assoc 1978;70(5):97-101.

[18] Baughman RP, Teirstein AS, Judson MA, et al. Clinical characteristics of patients in a case control study of sarcoidosis. Am J Respir Crit Care Med 2001;164(10 Pt 1):1885- 9.

[19] Henke CE, Henke G, Elveback LR, et al. The epidemiology of sarcoidosis in Rochester, Minnesota: a population-based study of incidence and survival. Am J Epidemiol 1986;123(5):840-5.

[20] Sharma SK, Mohan A. Sarcoidosis in India: not so rare. J Indian Acad Clin Med 2004;5:12-21.

[21] Sharma SK, Mohan A, Guleria JS. Clinical characteristics, pulmonary function abnormalities and outcome of prednisolone treatment in 106 patients with sarcoidosis. J Assoc Physicians India 2001;49:697-704.

[22] Nunes H, Soler P, Valeyre D. Pulmonary sarcoidosis. Allergy 2005;60(5):565-82.

[23] Douglas JG, Middleton WG, Gaddie J, et al. Sarcoidosis: a disorder commoner in non-smokers? Thorax 1986;41:787-91.

[24] Revsbech P. Is sarcoidosis related to exposure to pets or the housing conditions? A case-referent study. Sarcoidosis 1992;9(2):101-3.

[25] Baughman RP. Pulmonary sarcoidosis. Clin Chest Med 2004;25(3):521-30.

[26] Gupta D, Chetty M, Kumar N, et al. Anergy to tuberculin in sarcoidosis is not influenced by high prevalence of tuberculin sensitivity in the population. Sarcoidosis Vasc Diffuse Lung Dis 2003;20(1):40-5.

[27] Smith-Rohrberg D, Sharma SK. Tuberculin skin test among pulmonary sarcoidosis patients with and without tuberculosis: its utility for the screening of the two conditions in tuberculosis-endemic regions. Sarcoidosis Vasc Diffuse Lung Dis 2006;23(2):130-4.

[28] Reynolds HY. Sarcoidosis: impact of other illnesses on the presentation and management of multi-organ disease. Lung 2002;180(5):281-99.

[29] Lynch JP III, Kazerooni EA, Gay SE. Pulmonary sarcoidosis. Clin Chest Med 1997;18(4):755-85.

[30] Sharma SK, Rao DN, Pande JN, et al. Serum angiotensin-converting enzyme activity in sarcoidosis. Indian J Med Res 1987;85:638-44.

[31] Gupta SK. Sarcoidosis: a journey through 50 years. Indian J Chest Dis Allied Sci 2002;44(4):247-53.

[32] Goldstein RA, Israel HL, Becker KL, et al. The infrequency of hypercalcemia in sarcoidosis. Am J Med 1971;51(1):21-30.

[33] Sharma OP. Vitamin D, calcium, and sarcoidosis. Chest 1996;109(2):535-9.

[34] Hillerdal G, Nou E, Osterman K, et al. Sarcoidosis: epidemiology and prognosis. A 15-year European study. Am Rev Respir Dis 1984;130(1):29-32. 
[35] Johns CJ, Schonfeld SA, Scott PP, et al. Longitudinal study of chronic sarcoidosis with low-dose maintenance corticosteroid therapy. Outcome and complications. Ann NY Acad Sci 1986;465:702-12.

[36] Gottlieb JE, Israel HL, Steiner RM, et al. Outcome in sarcoidosis. The relationship of relapse to corticosteroid therapy. Chest 1997;111(3):623-31.

[37] Bambery P, Behera D, Gupta AK, et al. Sarcoidosis in north India: the clinical profile of 40 patients. Sarcoidosis 1987;4(2):155-8.

[38] Gupta SK, Mitra K, Chatterjee S, et al. Sarcoidosis in India. Br J Dis Chest 1985;79(3):275-83.

[39] Viswanathan R, Chakravarty S. Sarcoidosis. Ind J Chest Dis 1959;1:64-8.

[40] De MS, Chatterjee ML, Chatterjee BP. Sarcoidosis. Bull Cal Sch Trop Med 1968;16:66.

[41] Guleria JR, Wali JP. Sarcoidosis in India. JAPI 1971;19:91.

[42] Gupta SK. Sarcoidosis: a study in eastern India. J Ind Med Assoc 1977;68(12):245-7.

[43] Kashyap S, Kumar M, Pal LS, et al. Clinical profile of sarcoidosis in Himachal Pradesh, northern India. J Assoc Physicians India 1997;45:574-5.

[44] Siltzbach LE. Sarcoidosis: clinical features and management. Med Clin North Am 1967;51(2):483502.

[45] Romer FK. Presentation of sarcoidosis and outcome of pulmonary changes. Dan Med Bull 1982;29(1):27-32.

[46] Hunninghake GW, Gilbert S, Pueringer R, et al. Outcome of the treatment for sarcoidosis. Am J Respir Crit Care Med 1994;149(4 Pt 1):893-8.

[47] Chappell AG, Cheung WY, Hutchings HA. Sarcoidosis: a long-term follow-up study. Sarcoidosis Vasc Diffuse Lung Dis 2000;17(2):167-73.

[48] Pietinalho A, Ohmichi $M$, Lofroos AB, et al. The prognosis of pulmonary sarcoidosis in Finland and Hokkaido, Japan. A comparative five-year study of biopsy proven cases. Sarcoidosis Vasc Diffuse Lung Dis 2000;17(2):158-66.

[49] Kiter G, Musellim B, Cetinkaya E, et al. Clinical presentations and diagnostic work-up in sarcoidosis: a series of Turkish cases (clinics and diagnosis of sarcoidosis). Tuberkuloz ve Toraks Dergisi 2011;59(3):248-58.

[50] Ors F, Gumus S, Aydogan M, et al. HRCT findings of pulmonary sarcoidosis; relation to pulmonary function tests. Multidisciplinary Respiratory Medicine 2013;8:2-8.

[51] Carrillo-Perez DL, Apodaca-Chaveza EI, CarrilloMaravilla E, et al. Sarcoidosis: a single hospital-based study in a 24-year period. Rev Invest Clin 2015;67(1):33-8.
[52] Brauner MW, Grenier P, Mompoint D, et al. Pulmonary sarcoidosis: evaluation with high resolution CT. Radiology 1989;172(2):467-71.

[53] Sharma OP. Cutaneous sarcoidosis: clinical features and management. Chest 1972;61(4):320-5.

[54] Yanardag H, Pamuk ON, Karayel T. Cutaneous involvement in sarcoidosis: analysis of the features in 170 patients. Respir Med 2003;97(8):978-82.

[55] Lynch JP, Sharma OP, Baughman RP. Extrapulmo-nary sarcoidosis [in process citation]. Semin Respir Infect 1998;13:229-54.

[56] Chapman JT, Mehta AC. Bronchoscopy in sarcoidosis: diagnostic and therapeutic interventions. Curr Opin Pul Med 2003;9(5):402-7.

[57] Shorr AF, Torrington KG, Hnatiuk OW. Endobronchial biopsy for sarcoidosis: a prospective study. Chest 2001;120(1):109-14.

[58] Corsello BF, Lohaus GH, Funahashi A. Endobronchial mass lesion due to sarcoidosis: complete resolution with corticosteroids. Thorax 1983;38(2):157-8.

[59] Gupta D, Mahendran C, Aggarwal AN, et al. Endobronchial vis a vis transbronchial involvement on fiberoptic bronchoscopy in sarcoidosis. Sarcoidosis Vasc Diffuse Lung Dis 2001;18(1):91-2.

[60] Torrington KG, Shorr AF, Parker JW. Endobronchial disease and racial differences in pulmonary sarcoidosis. Chest 1997;111(3):619-22.

[61] Costabel U, Ohshimo S, Guzman J. Diagnosis of sarcoidosis. Curr Opin Pulm Med 2008;14(5):455-61.

[62] Drent $M$, van Nierop MA, Gerritsen FA, et al. A computer program using BALF analysis results as a diagnostic tool in interstitial lung diseases. Am J Respir Crit Care Med 1996;153(2):736-41.

[63] Winterbauer RH, Lammert J, Selland $M$, et al. Bronchoalveolar lavage cell populations in the diagnosis of sarcoidosis. Chest 1993;104(2):352-61.

[64] Thomeer M, Demedts M. Predictive value of CD4/CD8 ratio in bronchoalveolar lavage in the diagnosis of sarcoidosis. Sarcoidosis Vasc and Diffuse Lung Dis 1997;14(Suppl 1):36.

[65] Kantrow SP, Meyer KC, Kidd P, et al. The CD4/CD8 ratio in BAL fluid is highly variable in sarcoidosis. Eur Respir J 1997;10(12):2716-21.

[66] Danila E, Norkuniene J, Jurgauskiene L, et al. Diagnostic role of BAL fluid CD4/CD8 ratio in different radiographic and clinical forms of pulmonary sarcoidosis. Clin Respir J 2009;3(4):214-21. 